\title{
Estimation of the Period of Vibration of Existing Egypt RC Building Based on Experimental Data and Numerical Results Under the Effect of Soil-Structure Interaction
}

\author{
Ayman M. Ismail ${ }^{1}$, Ahmed Mohey Ibrahim $^{2}$ \\ ${ }^{1}$ Professor of Structural Engineering, HBRC, Egypt, \\ ${ }^{2}$ Doctor of Structural Engineering, HBRC, Egypt,
}

\begin{abstract}
Most seismic design codes generally provide formulas to be used for the estimation of the base shear and lateral loads. For the determination of the lateral loads, it is required to estimate first the fundamental vibration period of the building theoretically or experimentally. This fundamental period and its length are relevant to earthquake engineering applications on existing buildings, and must be treated very carefully. In various current codes and in the recommendations of many researches, empirical formulas relate the building fundamental period of vibration $(T)$ to the building overall height $(H)$ or the number of stories $(N)$ without consideration of the soil structure interaction (SSI). In the present study, a data set acquired of about 150 reinforced concrete building in Egypt using ambient vibration measurements (AVM) has been analyzed in order to investigate the fundamental period. Improved formulas for estimating the fundamental period of vibration $(T)$ of reinforced concrete moment-resisting frame buildings using regression analysis are developed by taking the effect (SSI). The results indicate that the value of coefficient (T) in the current international and Egyptian building codes' formulas should be modified to be function of the effect of (SSI). Comparisons between the periods determined using the proposed formula and the measured values show good agreement.
\end{abstract}

Keywords: Ambient vibration, fundamental period, infill walls, RC. buildings, soil-structure interaction.

\section{Introduction}

The determination of the natural period of vibration of a reinforced concrete structure is an essential procedure in earthquake design and assessment. In the last years many experimental and numerical studies as well as many research projects have been carried out in order to define in a simplified way the fundamental period of Reinforced Concrete buildings, Gallipoli et al.[1], Crowley and Pinho[2], Al-Nimry et al [3]. Particularly, empirical relationships between the height of a building type and its fundamental period of vibration have been sought, as they can be very useful in many applications. Simplified expressions are mandatory in large scale applications, where the period of a building (or of a class of buildings) needs to be estimated in assessing the seismic vulnerability at urban scale. Modern technology allows performing a detailed assessment of the dynamic properties of a building in a very short time, thus an empirical relationship between a building's main characteristics (structural typology, shape, dimensions, age, etc.) and its dynamic behavior can be obtained. On the basis of a classification scheme, the relationship can be applied to similar buildings over a large spatial extent, where building characteristics are obtained from quick field survey or from remote sensing.

Modal identification of existing buildings through the analysis of in-situ vibration measurements became a classic procedure for providing modal characteristics of a building, for studying the seismic response of buildings and even for damage detection. Modal characteristics are often identified from ambient vibration measurements and from seismic records. Ambient vibration testing is generally preferred to non-destructive forced vibration measurement techniques for obtaining the modal parameters of large structures for many reasons.

A structure can be adequately excited by wind, traffic, and human activities and the resulting motions can be readily measured with highly sensitive instruments. Expensive and cumbersome devices to excite the structure are therefore not needed. Consequently, the overall cost of the measurements conducted on a large structure is reduced.

Ambient vibration measurements of many buildings have been recorded across the world in the past to determine their dynamic properties, in particular, to ascertain the properties of the fundamental modes of vibration, Midorikawa [4], Negulescu et al. [5], Michel et al. [6], and Demetriu et al. [7] etc. It is also recognized that the experimental data from one region may not be used in another owing to the differences in the construction methods and materials.

Empirical expressions for the fundamental periods of idealized buildings, $\mathrm{T}=\mathrm{C}_{\mathrm{t}} \mathrm{H}^{\mathrm{x}}$, have been proposed by Housner and Brady [8]. Furthermore, relative studies for RC buildings have been investigated 
by Goel and Chopra [9,10], Rahimian et al [11], and Chiauzzi et. al.[12].

\section{Period Database}

The data that used in the regression analysis at this paper are that used by Ismail [13]. These available data on the fundamental period of buildings measured from their motions recorded under ambient vibration test. Table 1 shows the subset of this database pertaining 150 data points for $150 \mathrm{RC}$ MRF buildings with/without shear wall. From these data, it can be noticed that the significant difference of soil types for the measured buildings are present.

Table 1 Period Data for RC Buildings

\begin{tabular}{|c|c|c|c|c|c|c|c|c|c|}
\hline \multicolumn{2}{|c|}{ EL-Mokatem } & \multicolumn{2}{|c|}{ Naser City } & \multicolumn{2}{|c|}{ Maadi } & \multicolumn{2}{|c|}{ El-Haram } & \multicolumn{2}{|c|}{ Shoubra } \\
\hline $\begin{array}{c}\mathrm{H} \\
(\mathrm{m})\end{array}$ & $\mathrm{T}_{\mathrm{o}}(\mathrm{s})$. & $\begin{array}{c}\mathrm{H} \\
(\mathrm{m})\end{array}$ & $\begin{array}{c}\mathrm{T}_{\mathrm{O}} \\
\text { (S.) }\end{array}$ & $\begin{array}{c}\mathrm{H} \\
(\mathrm{m})\end{array}$ & $\begin{array}{c}\mathrm{T}_{\mathrm{o}} \\
\text { (s.) }\end{array}$ & $\begin{array}{c}\mathrm{H} \\
(\mathrm{m})\end{array}$ & $\begin{array}{c}\mathrm{T}_{\mathrm{o}} \\
\text { (S.) }\end{array}$ & $\begin{array}{c}\mathrm{H} \\
(\mathrm{m})\end{array}$ & $\begin{array}{c}\mathrm{T}_{\mathrm{o}} \\
\text { (S.) }\end{array}$ \\
\hline 28 & 0.67 & 28 & 0.91 & 125 & 3.18 & 28 & 0.97 & 21 & 0.78 \\
\hline 27 & 0.65 & 27 & 0.89 & 120 & 2.90 & 27 & 1.01 & 21 & 0.83 \\
\hline 28 & 0.48 & 28 & 0.91 & 131 & 3.10 & 28 & 1.03 & 30 & 1.09 \\
\hline 14 & 0.42 & 14 & 0.54 & 18 & 0.68 & 14 & 0.62 & 14 & 0.62 \\
\hline 38 & 0.60 & 14 & 0.49 & 18 & 0.64 & 14 & 0.55 & 14 & 0.55 \\
\hline 12 & 0.40 & 12 & 0.48 & 22 & 0.79 & 12 & 0.55 & 12 & 0.55 \\
\hline 15 & 0.43 & 15 & 0.57 & 22 & 0.76 & 15 & 0.92 & 15 & 0.92 \\
\hline 15 & 0.33 & 15 & 0.55 & 18 & 0.63 & 15 & 0.62 & 15 & 0.62 \\
\hline 33 & 0.75 & 33 & 1.15 & 18 & 0.71 & 33 & 1.30 & 33 & 1.30 \\
\hline 19 & 0.67 & 19 & 0.75 & 22 & 0.76 & 19 & 0.84 & 18 & 0.81 \\
\hline 14 & 0.37 & 14 & 0.54 & 14 & 0.54 & 14 & 0.79 & 14 & 0.69 \\
\hline 14 & 0.35 & 14 & 0.53 & 14 & 0.53 & 14 & 0.78 & 14 & 0.68 \\
\hline 14 & 0.38 & 14 & 0.51 & 14 & 0.51 & 14 & 0.76 & 14 & 0.66 \\
\hline 12 & 0.36 & 12 & 0.47 & 12 & 0.47 & 12 & 0.78 & 12 & 0.08 \\
\hline 15 & 0.43 & 15 & 0.56 & & & 15 & 1.06 & 13 & 0.92 \\
\hline 15 & 0.44 & 15 & 0.52 & & & 15 & 0.78 & 13 & 0.69 \\
\hline 33 & 0.71 & 33 & 0.94 & & & 33 & 1.52 & 30 & 1.40 \\
\hline 19 & 0.61 & 19 & 0.67 & & & 19 & 1.01 & 19 & 1.07 \\
\hline 14 & 0.25 & 14 & 0.38 & & & 14 & 0.58 & 14 & 0.60 \\
\hline 24 & 0.60 & 42 & 1.24 & & & 42 & 2.96 & 42 & 2.04 \\
\hline 14 & 0.30 & 46 & 1.32 & & & 46 & 3.23 & 46 & 1.82 \\
\hline 14 & 0.39 & 38 & 1.15 & & & 38 & 1.87 & 38 & 1.56 \\
\hline 12 & 0.22 & 24 & 0.81 & & & 24 & 1.22 & 24 & 1.00 \\
\hline 15 & 0.45 & 28 & 0.82 & & & 28 & 1.22 & 28 & 1.30 \\
\hline \multirow[t]{14}{*}{15} & 0.41 & 21 & 0.74 & & & 21 & 0.97 & 21 & 1.00 \\
\hline & & 18 & 0.66 & & & 18 & 0.99 & 18 & 1.05 \\
\hline & & 26 & 0.84 & & & 26 & 1.02 & 26 & 1.16 \\
\hline & & 46 & 1.49 & & & 46 & 1.68 & 46 & 1.24 \\
\hline & & 39 & 1.31 & & & 39 & 1.31 & 39 & 1.33 \\
\hline & & 46 & 1.31 & & & 46 & 1.49 & 46 & 1.51 \\
\hline & & 46 & 1.29 & & & 46 & 1.29 & 46 & 1.30 \\
\hline & & 46 & 1.25 & & & 46 & 1.25 & 46 & 1.26 \\
\hline & & 18 & 0.64 & & & 18 & 0.64 & 18 & 0.65 \\
\hline & & 16 & 0.59 & & & 16 & 0.66 & 16 & 0.68 \\
\hline & & 18 & 0.60 & & & 18 & 0.55 & 18 & 0.55 \\
\hline & & 22 & 0.70 & & & 22 & 0.84 & & \\
\hline & & 22 & 0.74 & & & 22 & 0.68 & & \\
\hline & & 24 & 0.57 & & & 24 & 0.64 & & \\
\hline \multicolumn{2}{|c|}{$\begin{array}{c}\text { Rock-crashed } \\
\text { soil }\end{array}$} & \multicolumn{2}{|c|}{$\begin{array}{l}\text { Stiff soil } \\
\text { class "B" }\end{array}$} & \multicolumn{2}{|c|}{$\begin{array}{l}\text { Medium to } \\
\text { Stiff soil } \\
\text { class "C" }\end{array}$} & \multicolumn{2}{|c|}{$\begin{array}{l}\text { Medium to } \\
\text { Stiff soil } \\
\text { class "C" }\end{array}$} & \multicolumn{2}{|c|}{$\begin{array}{l}\text { Medium to } \\
\text { Stiff soil } \\
\text { class "C" }\end{array}$} \\
\hline
\end{tabular}

Note:- $\mathrm{T}_{\mathrm{o}}$ is the measured fundamental period regardless direction or building stiffness.

\section{Evaluation of the Existing Formulas in Current Building Codes}

The determination of the natural period of vibration of a reinforced concrete structure is an essential procedure in earthquake design and assessment. An improved understanding of the global demands on a structure under a given seismic input can be obtained from this single characteristic. This property is dependent on the mass, strength and stiffness of the structure and is thus affected by many factors such as structural regularity, number of storeys and bays, section dimensions, infill panel properties, axial load magnitude, reinforcement ratio and extent of concrete cracking. For the seismic design of a reinforced concrete (RC) frame, the period of vibration will not be known a priori and thus simplified equations are employed in the seismic design codes to relate the fundamental period to the height of the frame. 
Many design codes (e.g. EC8 [14], ASCE7-10 [15], UBC-97[16]) provide simple relationships to calculate the fundamental period of vibration of building structures, mainly aimed at verifying if the lateral force method of analysis may be applied to determine the seismic effects. Typically, empirical heightperiod relationships are provided dependent only on the structural type (concrete frames, steel frames, masonry, etc.), but do not taking into account other important structural characteristics such as member stiffness, geometry, presence and position of masonry infills. These relationships have been developed keeping in mind force-based design. For this reason, they provide low estimates of period such that the lateral shear force is conservatively predicted from an acceleration spectrum.

In the European seismic design regulation, Eurocode-8 (EC8) [14] or Egyptian code 2012 [17], the period height relationship is specified for force-based design of moment resisting concrete frames and had the form:-

$T=0.075 H^{0.75}$

The Uniform Building Code 1997 (UBC97) states that the period shall be determined as following:

$T=\mathrm{C}_{\mathrm{t}} H^{0.75}$

Where, $\mathrm{C}_{\mathrm{t}}$ is equal to 0.073 when " $\mathrm{H}$ " is in meters, or 0.030 when "H" is in feet. Eq. 2 also applies to reinforced concrete moment-resisting frames as well as eccentrically braced frames. For all other buildings $C_{t}$ is equal to 0.0488 in the SI system or 0.02 in the imperial system, respectively. In this formulation, " $\mathrm{H}$ " is the height of the building above the base. UBC-97 [16] also indicates that the fundamental period can be calculated using a rational analysis such as Rayleigh's method or Eigen-value solution. In this case, the base shear should not be less than $80 \%$ of the base shear calculated by Eq. 2 .

For ASCE7-10 [15] the following equations are given for prediction of fundamental natural frequencies:-

$T=0.044 H^{0.9}$

For reinforced concrete moment resisting frame

$T=0.073 H^{0.75}$

For eccentrically braced frames and

$T=0.049 H^{0.75}$

For Reinforced concrete buildings or building with masonry, shear wall.

Note that the code formula provides the same period in the two directions as long as the lateral resisting systems in these directions are identical. In most seismic building codes, the role of the soil structure interaction is usually considered beneficial to the structural system under seismic loading since it lengthens the lateral fundamental period and leads to higher damping of the system. This conclusion could be misleading. Recent case studies and post-seismic observations suggest that the soil structure interaction can be detrimental and neglecting its influence could lead to unsafe design for both the superstructure and the foundation especially for structures founded on soft soil, Mylonakis and Gazetas, [18], Stewart et al.[19,20], Mylonakis and Gazetas [21], Boris et al [22], Khalil et al. [23] and Gullu and Pala [24]. They established that the seismic response of a Single-Degree of Freedom (SDOF) structure with a surface foundation can be predicted by an equivalent fixed-base SDOF with modified period. The flexible-base period $\bar{T}$ is evaluated from FEMA450 [25] for a structure with a surface foundation as follow:

$$
\begin{gathered}
\bar{T}=\mathrm{T} \sqrt{1+\frac{\bar{k}}{K_{y}}}\left[1+\frac{K_{y} \bar{h}^{2}}{K_{\theta}}\right] \\
\bar{k}=4 \pi^{2}\left(\frac{\bar{W}}{g T^{2}}\right)
\end{gathered}
$$

Where

$\mathrm{T}=$ denotes the fixed-base system period,

$\bar{k}=$ the stiffness of the fixed-base structure,

$\mathrm{k}_{\mathrm{y}}$ and $\mathrm{k}_{\theta}$ the lateral stiffness and rocking stiffness of the foundation, 
$\bar{h}=$ the effective height of the structure which shall be taken as 0.7 times the total height, $\mathrm{h}_{\mathrm{n}}$,except that for structures where the gravity load is effectively concentrated at a single level,it shall be taken as the height to that level,

$\bar{W}=$ the effective gravity load of the structure, which shall be taken as $0.7 \mathrm{~W}$, except that for structures where the gravity load is concentrated at a single level, it shall be taken equal to $\mathrm{W}$,

$\mathrm{g}=$ the acceleration due to gravity respectively.

From the field measurements presented previously in this paper, it was shown that measured periods of existing building is longer than that given by most empirical code formulas. Figure 1 shows significant difference among the values obtained using above-mentioned different formulae. It is clear from that figure that the results obtained from Codes' formulae of UBC97, EC8-2006 are almost the same. The periods obtained using experimental works by researcher are almost longer than that using Codes' formulae. At the same time, it was observed that buildings with the same height have different periods. The differences in the measured periods for building with the same height prove that, some major parameters influencing in the period are not considered in codes equations. In addition, from this figure, the periods obtained using formulae recommended by different codes in some cases, reach more than twice times the values obtained from field measurements for Cairo buildings. Ismail [13] proposed equation gives different values from that obtained using EC8 or UBC97. This due infill brick work type as well as moderate soil type.

As shown from figure 1, with increasing soil stiffening, the measured period tend to decrease especially with soil type "A" and "B" as classified by ECP-201 (2012). In other hand, the measured period in some cases is shorter than that of the seismic codes. These cases lead to increase/decrease of the spectral acceleration coefficient, which causes the increase/decrease of designbase shear.

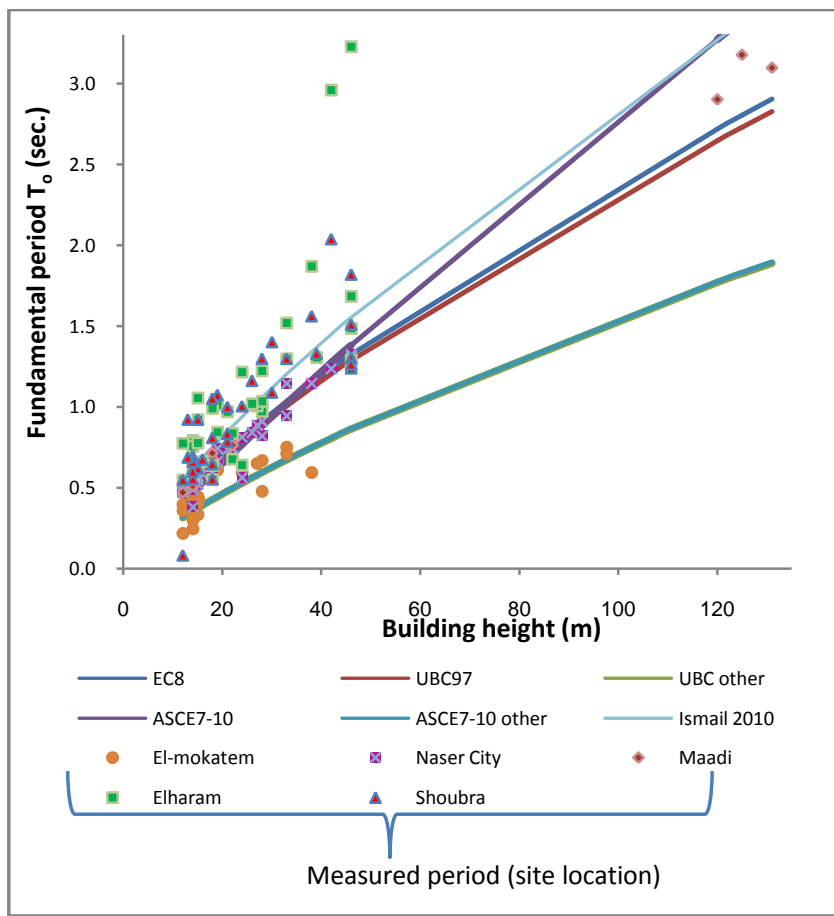

Figure 1 Comparison of measured fundamental period $\mathrm{T}_{\mathrm{o}}$ and codes formulae for $\mathrm{RC}$ building

\section{Improved Expression to Estimate the Fundamental Period of RC Building}

From the code formulas and recommended formulas in the recent researches, the suggested formula, which is adopted in the present paper, is of the form:

$$
\mathrm{T}=\alpha \mathrm{H}^{\beta} \mathrm{k}^{\gamma}
$$

In which constants, $\alpha, \beta$ and $\gamma$ depend on building and soil properties respectively. " $H "$ is the building height from the foundation to point located on a complete top roof and "k" is the elastic springs represent the soil properties in $\mathrm{Kg} / \mathrm{cm}^{3}$.

Using computer software, multiple regression analysis technique is developed for the suggested 
equation to obtain the constants, $\alpha, \beta$ and $\gamma$ of the plane represented by equation 8 . This form is adopted in the present work and constants, $\alpha, \beta$ and $\gamma$ determined by regression analysis of the measured period data.

The regression analysis technique depends on minimizing the squared error between the measured and computed periods. This procedure leads to values, $\alpha, \beta$ and $\gamma$ for equation 8 to represent the best fit to the measured period data using least square method.

In fact, it is hard to have a field period measurement for building with finalized reinforced concrete Skelton without infill wall. As indicated in NBCC-95 [26], there is a very good agreement between the predictions and the analytical fundamental periods for buildings of 40 to $60 \mathrm{~m}$. height range when exterior frames are fully in-filled with masonry walls. The computed values vary only $3 \%$ to $10 \%$ compared to the code periods. As expected, the observed trend indicates that when the computed periods approach the code's estimation, further stiffening of the structure would not affect the fundamental period considerably. Many researchers study the effect of the infill wall on the fundamental building (Martha [27]. He also concluded that the effect of infill walls will reduce the fundamental period by about 5-20\%. However, verification of the fundamental period of analytical models with existing building models is still required.

The simplified typical form of the general form of an empirical formula, equation 8 is as follows:

$\alpha=C_{t}, \beta=x, \gamma=y$

$\mathrm{T}=\mathrm{C}_{\mathrm{t}} \mathrm{H}^{\mathrm{x}} \mathrm{k}^{\mathrm{y}}$

Where $C_{t}, x$ and $y$ are coefficients derived by using the regression analysis technique. For design values of fundamental period and based on recommendation of NBCC-95 by increasing the values of measured periods by about $20 \%$ leads to have a good relations between exact building behavior and the predicted periods used in the design purpose. By doing that and use the field measurements of the fundamental period multiplied by a certain values for the effects of infill walls the following equation can be obtained using the regression analysis technique.

$$
\mathrm{T}=0.075 \mathrm{H}^{0.75} \mathrm{k}^{-0.315}
$$

Figure 2 shows the ratios between the modified observed and predicted values of the fundamental period from equation 10. From this figure, it is clear that there is good correlation between the modified observed and predicted periods.

The goodness of fit statistics has been checked. The results values of checked regression analysis and corresponding mathematical properties are presented in table 2.

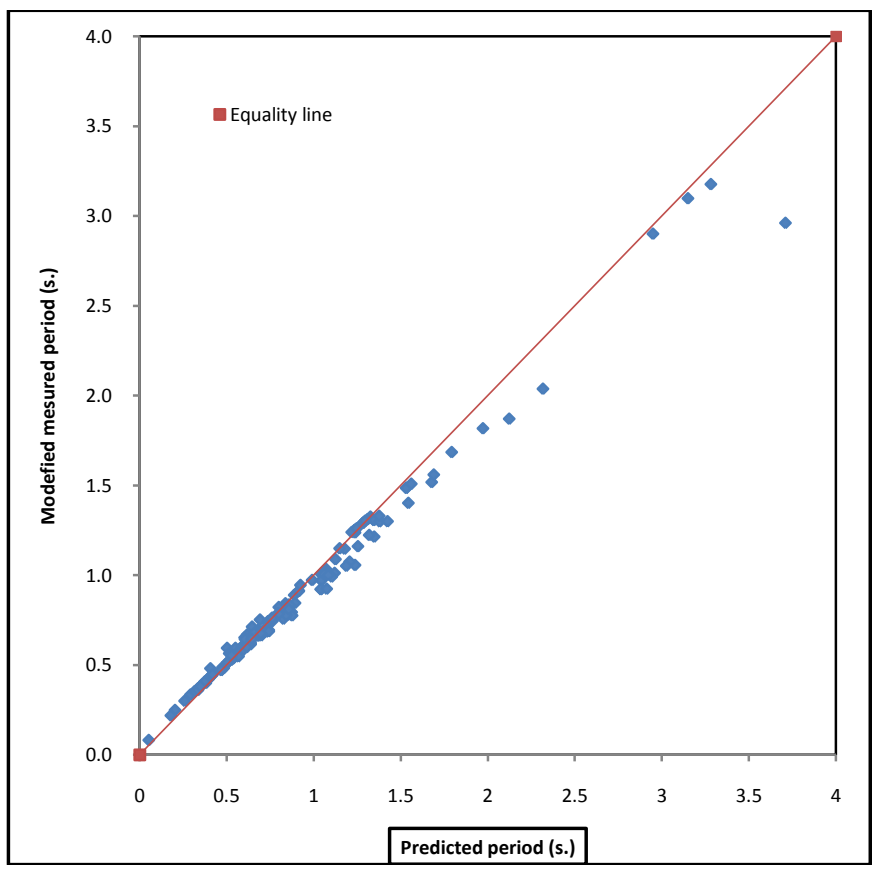

Figure 2 Verification of periods obtained from proposed equation, $\mathrm{T}=0.075 \mathrm{H}^{0.75} \mathrm{k}^{-0.315}$

Table 2 Regression Variable Results 


\begin{tabular}{|l|l|l|l|l|}
\hline Variable & $\begin{array}{l}\text { Variable } \\
\text { Value }\end{array}$ & $\begin{array}{l}\text { Standard } \\
\text { Error }\end{array}$ & t-ratio & $\begin{array}{l}\text { Prob. } \\
\text { (t) }\end{array}$ \\
\hline $\boldsymbol{\alpha}$ & 0.075 & 0.0326 & 1.474 & 0.053 \\
\hline $\boldsymbol{\beta}$ & 0.75 & $3.8935 \mathrm{E}-03$ & 1.615 & 0.0 \\
\hline $\boldsymbol{\gamma}$ & -0.315 & 0.1015 & -0.833 & 0.4082 \\
\hline
\end{tabular}

Figure 3 shows a comparison of results obtained using the proposed equations (Equation. 10) and modified filed measurements of the fundamental period $\mathrm{T}_{\mathrm{o}}$. A comparison between the proposed equation and code formulas, (United States of America ASCE7 (2010), Euro-code (2006), and UBC97, are illustrated in figure 4 for upper limits represents the very weak soil and the lower limits which represents the very stiff soil.

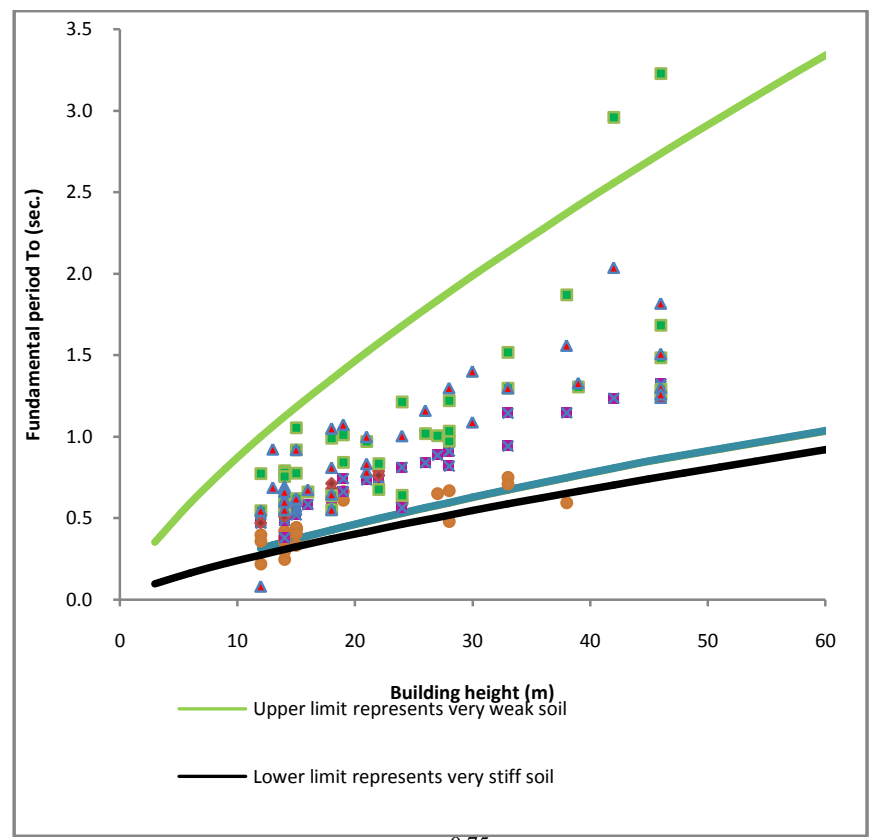

Figure 3 Comparison of proposed equation, $\mathrm{T}=0.075 \mathrm{H}^{0.75} \mathrm{k}^{-0.315}$, with modified filed measurements of the fundamental period $\left(\mathrm{T}_{\mathrm{o}}\right)$

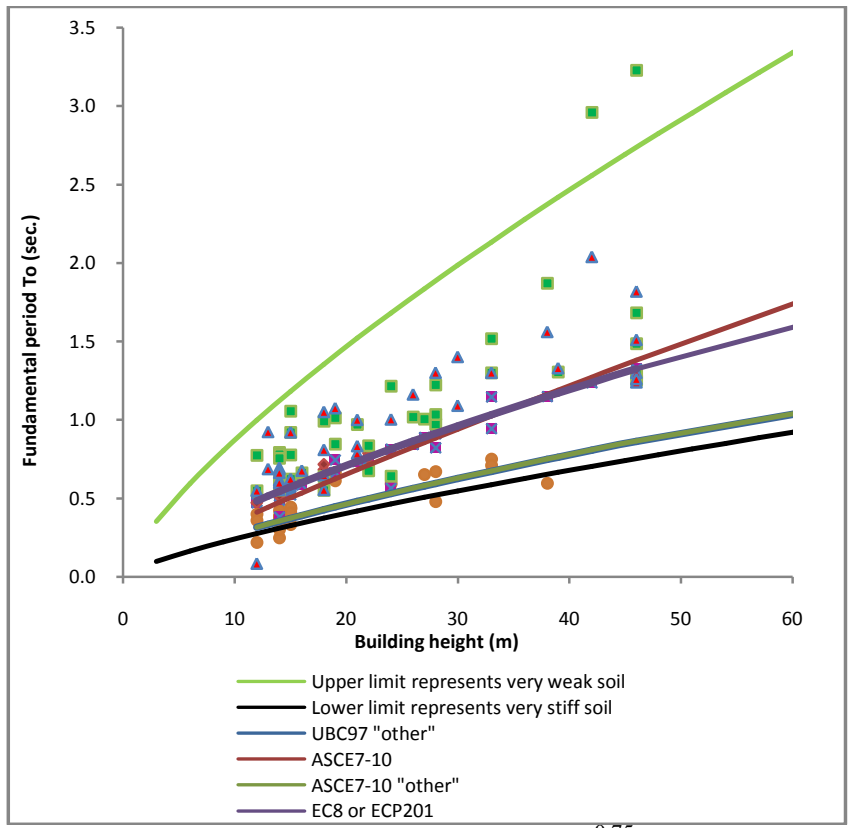

Figure 4 Comparison of proposed equation, $\mathrm{T}=0.075 \mathrm{H}^{0.75} \mathrm{k}^{-0.315}$, with codes formulae

\section{Conclusion}


The creation of a data-base with frequency information on a large amount of different buildings, where elements dealing with the geometry, in plan and height, type of structure and foundation, soil characteristics, presence of "infill walls", etc., is of great potential to provide a better knowledge of building performances.

The equation type $\mathrm{T}=\mathrm{C}_{\mathrm{t}} \mathrm{H}^{\mathrm{x}}$ is still the most common and simple way to express the variation of period for the different building types and regional situations, and has been adopted in many countries in Europe and LatinAmerica to represent their buildings, through clear differences in construction types, materials and existing loads.

The present study makes an effort to evaluate the effect of soil-structure interaction on primary dynamic characteristics of RC buildings based on ambient vibration measurement (AVM) on Egypt. The following are the major inferences from the present paper:-

a) Natural period of the system increases when the ground becoming softer.

b) Natural period of the system on rigid base coincided very well with that of frame resting on soil of very large stiffness. Further, the empirical period formula which is used to estimate seismic loads and based on general properties of the buildings should include effect of soil properties beside height $\mathrm{H}$.

c) The upper and lower limit of the proposed equation 10 satisfies in most cases both the range between very weak soil to very stiff soil.

d) It is recommended, to include empirical period formula in Egyptian code including soil properties beside height $\mathrm{H}$.

e) Natural period computed by empirical equation available in the codes provisions needs a thorough scrutiny.

f) The study shows that the effect of soil-structure interaction may appreciably alter the lateral natural periods of any structure. This is the primary parameter, which regulates the seismic lateral response of the building frames. Thus, evaluation of this parameter without considering soil-structure interaction may cause serious errors in seismic design.

Regression analysis that led to the recommended formula should be increased on larger data sets including buildings in other parts of the Egyptian cities where building and soil properties are significantly different than that of available data.

\section{References}

[1] Gallipoli MR, Mucciarelli M, Vona M. (2009)"Empirical estimate of fundamental frequencies and damping for Italian buildings", Earthquake Engineering and Structural Dynamic Vol. 38, pp. 973-988.

[2] Crowley H, and Pinho R., (2010) "Revisiting Eurocode 8 formulae for periods of vibration and their employment in linear seismic Analysis" Earthquake Engineering and Structural Dynamics; Vol. 39(2), pp.223-235.

[3] Al-Nimry, N., Resheidat, M. and Al-Jamal, M. (2014) "Ambient vibration testing of low and medium rise in-filled RC frame buildings in Jordan" Soil Dynamics and Earthquake Engineering Vol.59, pp. 21-29.

[4] Midorikawa, S.(1990) "Ambient vibration test of buildings in Santiago and Viña del Mar", A report on the Chile-Japan joint study project on seismic design of structures, The Japan international cooperation agency.

[5] Negulescu C., Radoi, R., Aldea, A. (2004) "Microtremor measurement for evaluation of building vibration characteristics", Report, National Center for Seismic Risk Reduction, Bucharest.

[6] Michel C., Guéguen P., Bard P.Y. (2008) "Dynamic parameters of structures extracted from ambient vibration measurements", Soil Dynamics and Earthquake Engineering; Vol. 28 (8), pp. 593-604.

[7] Demetriu, S. and Aldea, A. (2012) "Modal parameters of RC frame structure identified from ambient vibration measurements" 15 WCEE, Lisboan.

[8] Housner, G. W. and Brady, A. G. (1963)"Natural Periods of Vibration of Buildings," Journal of Engineering Mechanics Division, Proceedings of ASCE, Vol. 89, No. EM4, August, pp. 31-65.

[9] Goel, R. K. and Chopra, A. K.(1998)"Period formulas for Concrete Shear Wall Buildings" Journal of Structural Engineering, Vol. 124(4), pp. 426-433.

[10] Goel, R. K. and Chopra, A. K.(1997)"Period formulas for moment-resisting frame buildings" Journal of Structural Engineering; Vol. 123(11), pp.1454-1461.

[11] Rahimian, M., Mazroi, A., Momayes, A. and Jokar, N., (2004) "Reconniassance study of the Natural Period of RC Buildings for Iranian Seismic code provision" 13th World Conference on Earthquake Engineering, Vancouver, B.C., Canada.

[12] Chiauzzi L., Masi A. , Mucciarelli M., Cassidy J. F., Kutyn K., Traber J., Ventura C. and Yao F. ,(2012) "Estimate of fundamental period of reinforced concrete buildings: code provisions vs. experimental measures in Victoria and Vancouver (BC, Canada)"15WCEE, Lisboan.

[13] Ismail A. M. (2010) "Evaluation of code period formula through In Situ Measurements Of Egypt RC Buildings", Civil Engineering Research Magazine (CERM), Faculty of Engineering, Al-Azhar University, Cairo, Egypt, vol.32,No. 1, pp.342-349.

[14] EC8-CEN, (2006) Eurocode 8: "Design of structures for earthquake resistance", Part 1: General rules, seismic actions and rules for buildings, ComiteEuropeen de Normalisation, Brussels.

[15] UBC (1997) "Uniform building Code" International Conference of Building Officials, USA.

[16] ASCE 7-10 (2010) "Minimum Design Loads for Buildings and Other Structures", Published by the American Society of Civil Engineers, ASCE/SEI 7-10.

[17] The Egyptian Loading Code, ECP-201 (2012), pp. 108-158.

[18] Mylonakis G. and Gazetas G. (2000) "Seismic Soil-Structure Interaction: Beneficial or Detrimental?" Journal of Earthquake Engineering, Vol. 4, pp. 277-301.

[19] Stewart, JP, GL Fenves, and RB Seed (1999) "Seismic soil-structure interaction in buildings. I: Analytical aspects," J. Geotech. \&Geoenv. Engrg., ASCE, Vol. 125, No. (1), pp. 26-37.

[20] Stewart, JP, RB Seed, and GL Fenves (1999) "Seismic soil-structure interaction in buildings. II: Empirical findings," J. Geotech. \&Geoenv. Engrg., ASCE, Vol. 125, No. (1), pp. 38-48. 
[21] Mylonakis G. and Gazetas G.(1998) "Vertical Vibration and Additional Distress of Grouped Piles in Layered Soil", Soils and Foundations, Japanese Geotechnical Society; Vol. 38, pp.1-14.

[22] Boris Jeremi'c, SashiKunnath and Feng Xiong, (2004) "Influence of Soil-Structure interaction on Seismic Response of Bridges", International Journal for Engineering Structures, Vol. 26, Issue 3, pp. 391-402.

[23] Khalil, L. ,Sadek, M. and Shahhrour, I.(2007) " Influence of the soil-structure interaction (SSI) on the fundamental frequency of structures", 4th International Conference on Earthquake Geotechnical Engineering, June 25-28.

[24] Gullu, H. and Pala, M. (2014)" On the resonance effect by dynamic soil-structure interaction: a revelation study", J. Nat Hazards, Springer Science Business Media Dordrecht, Vol. 72, No. 2 , pp 827-847.

[25] Federal Emergency Management Agency, FEMA-450 (2004), Pre-standard and Commentary for Seismic Rehabilitation of Buildings. Washington DC.

[26] National Building Code of Canada (NBCC-95) (1996), National Research Council of Canada, Ottawa, Ontario.

[27] Martha D. Morales(2000) "Fundamental period of vibration for reinforced concrete buildings", Master of Applied Sciences in Structural Engineering, Department of Civil Engineering University of Ottawa Ottawa, Canada July. 